AG:DP/AFG/90/002

Terminal Report

\title{
UTILIZATION OF REMOTE SENSING FOR INVENTORY AND MONITORING OF AGRICULTURAL LAND
}

\section{AFGHANISTATN}

PROJECT FINDINGS AND RECOMMENDATIONS

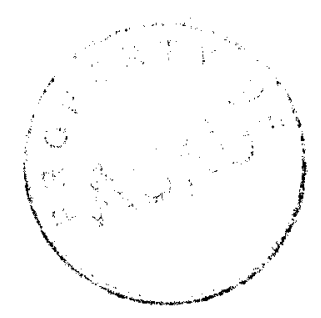

UNITED NATIONS DEVELOPMENT PROGRAMME 
AG:DP/AFG/90/002

Terminal Report

\section{UTILIZATION OF REMOTE SENSING FOR INVENTORY AND MONITORING OF AGRICULTURAL LAND}

\section{AFGHANISTAN}

PROJECT FINDINGS AND RECOMMENDATIONS

Report prepared for the Government of Afghanistan by

the Food and Agriculture Organization of the United Nations acting as executing agency for the United Nations Development Programme

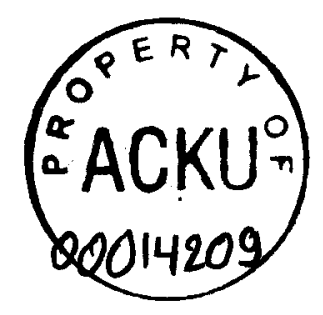

UNITED NATIONS DEVELOPMENT PROGRAMME

FOOD AND AGRICULTURE ORGANIZATION OF THE UNITED NATIONS 
The designations employed and the presentation of the material in this document do not imply the expression of any opinion whatsoever on the part of the United Nations or the Food and Agriculture Organization of the United Nations concerning the legal status of any country, territory, city or area or of its authorities, or concerning the delimitation of its frontiers or boundaries. 
The Food and Agriculture Organization is greatly indebted to all those who assisted in the implementation of the project by providing information, advice and facilities. 


\section{TABLE OF CONTENTS}

$\underline{\text { Page }}$

$\begin{array}{lc}\text { LIST OF ABBREVIATIONS } & \text { VI }\end{array}$

1. INTRODUCTION 1

1.1 Project background 1

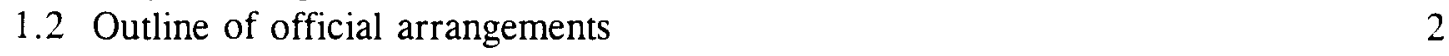

1.3 Project objectives $\quad 3$

2. RESULTS AND CONCLUSIONS 4

2.1 Project implementation 4

2.2 Data acquisition and processing 4

2.3 Interpretation of the satellite photomaps 5

2.4 Database generation $\quad 5$

2.5 Equipment provided $\quad 5$

$\begin{array}{ll}2.6 & \text { Training }\end{array}$

$\begin{array}{lll}2.7 & \text { Satellite photomap products } & 7\end{array}$

$\begin{array}{ll}2.8 \text { Cartographic outputs } & 7\end{array}$

2.8.1 Land cover maps at 1:250 000

2.8.2 National land cover map of Afghanistan 8

2.8.3 Provincial land cover atlas of Afghanistan 9

2.8.4 Conclusion 9

2.9 Land cover digital database $\quad 10$

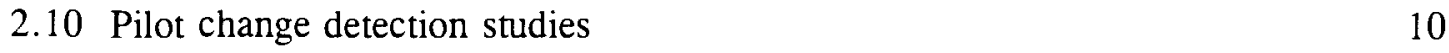

2.10.1 Vegetation change detection study 10

2.10.2 Change detection using Landsat TM 11

2.11 General conclusions 11

3. RECOMMENDATIONS 13

$\begin{array}{llr}\text { Appendix 1 } & \text { PROJECT STAFF } & 15\end{array}$

$\begin{array}{llr}\text { Appendix } 2 & \text { FELLOWSHIPS AND STUDY TOURS } & 16\end{array}$

Appendix $3 \quad$ MAJOR ITEMS PROCURED BY THE PROJECT 17

$\begin{array}{llr}\text { Appendix } 4 & \text { PROJECT PUBLICATIONS }\end{array}$ 


\section{LIST OF ABBREVIATIONS}

AGCHO Afghanistan Geodesy and Cartography Head Office

GIS geographical information system

GPS Global Positioning System

LAC Large Area Coverage [NOAA]

NOAA National Oceanic and Atmospheric Administration

RSC Remote Sensing Centre [at FAO Headquarters]

TM Thematic Mapper 


\section{INTRODUCTION}

\subsection{PROJECT BACKGROUND}

In Afghanistan, in former times, there existed a well-balanced ecological system comprising a way of life and economic agricultural practice, as well as natural endowments, resources and social conditions. This guaranteed the self-contained ecosystems but limited the farmer's living to a low economic standard. In the $1980 \mathrm{~s}$, this balance was endangered to the point of being virtually destroyed. A lack of labourers of active age, the abandonment of land, rapid deterioration in infrastructure, a negative balance of trade and the rapid growth of cities all combined to threaten the stability and even the survival of the traditional social pattern. Such cultural processes have affected the landscape, which could be used as a very sensitive indicator of these changes. However, no accurate basic information on current land cover and land potential was available for decision making or for comprehensive development planning. No new countrywide or regional agricultural census had ever been carried out and the various regional feasibility projects in the pipeline differed greatly in their range and scope.

This severe shortage of information - both quantitative and qualitative, at regional as well as all-country level - on natural resource endowment (renewable and non-renewable, including agriculture, natural vegetation, forest, water, minerals and energy) was proving to be a major limiting factor in proper planning and development. The problem had been exacerbated in the 1980 s as a consequence of the severely restricted mobility and difficulty of field data collection.

The land cover data in the various ministries was at least twenty to thirty years old, and inconsistent in terms of legend, scale, content, relevance and reliability. New data on the status of agriculture and other natural-resources-related parameters was not being collected on a regular basis and the institutional capacity to analyse data was clearly constrained. The net result was that the agricultural planning capacity of the country had been inhibited.

The economy of Afghanistan remained essentially agrarian, and as such the rehabilitation and development of the agricultural sector was accorded the highest priority in both the national planning of the Government of Afghanistan and the assistance programme of the United Nations.

Estimates indicated that whereas over $80 \%$ of the population of Afghanistan had derived its livelihood directly from the agricultural sector and other rural-based activities in the 1970s, by the time of project formulation, the status of the country's production from this sector appeared 
to demonstrate a noticeable decline in comparison with previous years, to about half the 1978 level. Undoubtedly, this decline was attributable to a large extent on the ongoing conflicts in Afghanistan.

In view of the above, there existed, at that time an urgent need for:

- accurate and rapidly acquired data that could form the basis for an inventory of agricultural lands in Afghanistan;

- the generation of reliable land cover maps of Afghanistan;

- the assessment of changes in the land cover and vegetation coverage in the previous two decades and recognition of important trends in this change process; and

- ultimately, the establishment of an ability to update such information in a practical and timely manner, so as to have at hand reliable information for future day-to-day decision making in this respect.

To meet the above needs, the utilization of remote sensing technology and geographical information system (GIS) techniques, and in particular the use of recently acquired satellite imagery and the subsequent creation of an agricultural land cover database as a basis for inventory and monitoring of agricultural lands in Afghanistan, was seen as most appropriate.

However, as the necessary equipment and expertise was not available in Afghanistan, the Government of Afghanistan requested UNDP assistance to implement the process. This assistance was approved and resulted in the project reported here.

\subsection{OUTLINE OF OFFICIAL ARRANGEMENTS}

The Project Document for project AFG/90/002, Utilization of remote sensing for inventory and monitoring of agricultural land in Afghanistan, was signed by the Government of Afghanistan on 14 May 1991, and by UNDP and by FAO, the Executing Agency, on 15 May 1991. The Afghan Geodesy and Cartography Head Office (AGCHO) was designated the government agency responsible for project implementation. The indicative donor budget was \$US 564350 , with a Government of Afghanistan contribution-in-kind equivalent to Af 2282500.

The initially envisaged starting date of the project was April 1991, but due to various delays, the effective starting date of the project was January 1992. The expected duration of the project at the time of its inception was 24 months. Both the timetable and the budget were subject to revision. The donor contribution as finally adjusted was SUS 2176356 , and the project 
terminated nominally in November 1995. A number of elements were still outstanding at that time, and funds were provided from FAO/TCP sources to enable completion of the main project outputs. Although the TCP support is reported separately, the activities implemented with TCP support are included in this report as appropriate.

\subsection{PROJECT OBJECTIVES}

The Development Objective was to strengthen the Government's capacity to manage agricultural land resources at the national and sub-national level by increasing the quality and widening the range of information available for planning in the sector.

The Immediate Objectives were to:

- provide evidence/location of changes between past and present land cover to orientate rehabilitation programmes; and

- train relevant Government staff in production and interpretation of satellite imagery, use of remote sensing techniques in rural rehabilitation and sectoral planning, and enhance managerial knowledge in the material and equipment needed for the generation of thematic maps from satellite data. 


\section{RESULTS AND CONCLUSIONS}

\subsection{PROJECT IMPLEMENTATION}

The project was implemented at the Remote Sensing Centre (RSC) in FAO Headquarters in Rome.

All equipment supplied under the project (see Appendix 3) was used in RSC or in the field, and was to be transferred to the Government of Afghanistan when circumstances permitted.

The AGCHO supplied a series of base maps, comprising one set each of 1:100 000 Topographical Maps; 1:100 000 Topographical Maps with 1972 land cover; 1:250 000 Topographical Maps with province boundaries; 1:250 000 Topographical Maps without boundaries; and 1:500 000 Topographical Maps. In addition, several general maps at various scales were supplied.

\subsection{DATA ACQUISITION AND PROCESSING}

Landsat satellite data of Afghanistan was ordered. This data - which was acquired predominantly in the spring and summer of 1991 - was used to prepare multiple photographic copies of 82 , $1^{\circ} \times 1^{\circ}$ geometrically corrected photomaps covering the whole of Afghanistan.

The satellite photomaps were generated by false colour composition of bands 2,3 and 4 of the Thematic Mapper (TM) sensor of the Landsat satellite, followed by geocoding of the data through extensive geometric correction using existing topographic maps. The processing of the satellite data was undertaken through a sub-contractor, who also assisted the project in the preparation of the Change Detection Pilot Products, such as the National Oceanic and Atmospheric Administration (NOAA) Large Area Coverage (LAC) Vegetation Index.

A full set of the Photomaps were also printed as offset litho maps in 500 copies at a scale of 1:250 000 for future use by the various ministries of the Government of Afghanistan. 


\subsection{INTERPRETATION OF THE SATELLITE PHOTOMAPS}

The satellite photomaps were interpreted and a land cover map of Afghanistan was prepared. The interpretation was carried out using 1:100 000, and occasionally 1:250 000, Landsat TM Photomaps.

The interpretation programme was complemented by a ground data collection programme in 1993, following training by the project of data collection personnel. This programme was implemented primarily to validate the interpretation of the data effected at RSC. This ground truth programme was necessary for validation of the satellite imagery interpretations. Initially, it had been planned that the ground truth operation would be to be undertaken, using AGCHO Head Office and Provincial personnel under the supervision of the project staff. This however proved impossible due to events outside the project's control, and the work was carried out using an alternative NGO arrangement through the Swedish Committee. Notwithstanding the problems, the results of the ground truth programme were satisfactory and greatly assisted the finalization of the land cover mapping.

In addition, to further enhance and update the land cover database, supplementary satellite data, such as 1993 Landsat TM coverage of parts of the country and KFA high-resolution space imagery, were also used.

\subsection{DATABASE GENERATION}

A multidate digital database of the land cover of Afghanistan was generated using the 1993 land cover dataset and the 1972 land cover map of Afghanistan. The 1972 land cover dataset had been produced over a period of 10 to 15 years by interpretation of aerial photographs and extensive ground surveys.

The project database was generated through the digitization of both the 1972 and 1993 maps, and database also included data relating to the hydrography (river and canal network) and the road network, derived from existing base maps and as updated from recent satellite data.

\subsection{EQUIPMENT PROVIDED}

In order to carry out the interpretation of the satellite data and to generate the digital land cover database, the project established a PC-based image processing and GIS laboratory within RSC. 
This involved the purchase of two PC computers and appropriate peripheral input and output equipment.

The project also used Global Positioning System (GPS) technology when collecting ground truth data for validation of the interpretation of the imagery.

The equipment, software and remote sensing data sets purchased by the project are listed in Appendix 3.

\subsection{TRAINING}

The Project Document had foreseen a number of training activities, including fellowships, study tours and in-country user training. The disturbed civil security conditions in Afghanistan precluded such activities in the period of the project, so training was limited to providing one expert from $\mathrm{AGCHO}$ and one expert from the Forestry Division of the Ministry of Agriculture with training in interpretation of satellite imagery and in operation of the natural resource database.

The study tours component was used to bring senior officers of $\mathrm{AGCHO}$, including the National Project Director, to RSC to confer with the project staff regarding the form and format of the project output products and for quality control of the local-language legends to the printed map products. The extent of coordination needed for finalization of the map products was much more than anticipated, involving 5.5 work-months rather than the scheduled one short study tour.

Details of fellowships and study tours are given in Appendix 2.

In total, the amount of training carried out under the project was considerably less than originally planned: a total of about 3 work-months rather that the planned 12 work-months.

Furthermore, the four-week workshop envisaged for the training of experts from various organizations in Afghanistan, and the transfer and handing over of the project to AGCHO, had not taken place by project end. The prime reason was that such a workshop could only be effected after the completion of all project outputs, and this was expected to be achieved in mid1997.

Other than the difficulties of communications and coordination of schedules with the counterpart agency in Kabul during these difficult times, coupled with the fact that the intermittent nature of the presence of some of the project staff did not lend itself very well to scheduling of short training courses, a major reason for the non-realization of all the training originally 
envisaged was an unexpected increase in the workload of project staff resulting from a need to carry out a much more extensive than originally envisaged quality control of the land cover database.

\subsection{SATELLITE PHOTOMAP PRODUCTS}

The project produced five major sets of satellite photomaps. Each set fully covered the territory of Afghanistan.

Landsat TM Colour Photomaps were produced at 1:100 000, with each map covering $1^{\circ} \times 1^{\circ}$. The maps were delivered both as a single master film transparency and as five sets of photographic prints.

Landsat TM Colour Photomaps were also produced at 1:250 000, each covering $1^{\circ} \times 1^{\circ}$. The 1:250 000 maps were supplied as a single, master film transparency, as five full sets of photographic prints, and as 500 full sets printed by colour offset lithography.

These satellite photomaps first and foremost provided the basis for the image interpretation carried out for the preparation of the land cover maps, but, in addition, this data constituted a very valuable resource for the preparation of maps related to a wide range of other disciplines germane to the natural resources of Afghanistan, as well as infrastructural applications, such as planning of transportation networks and urban development.

These products were expected to be very effectively utilized by all ministries and organizations in Afghanistan whose activities dealt with geography, the environment, energy and natural resources. It was expected that the wide dissemination of these products, made possible by the provision of printed copies of the photomaps, would also have a major effect on the coordination of activities in the various user agencies in Afghanistan, and would eventually enable AGCHO to compile a very comprehensive database of Afghanistan's natural resources. This database would of course serve as a vital management tool.

\subsection{CARTOGRAPHIC OUTPUTS}

\subsubsection{Land cover maps at 1:250 000}

A complete map coverage of the land cover of Afghanistan was generated and printed out as 82 , $1^{\circ} \times 1^{\circ}$ map sheets at a scale of $1: 250000$. 
Over 20 classes of land cover were recognized and mapped, comprising the full spectrum of agricultural covers, including various irrigated and rainfed agricultural lands, orchards, vineyards, gardens and woodlands, in addition to general categories such as rangelands, barren lands, marshes and so on.

The map sheets measured approximately $70 \times 45 \mathrm{~cm}$, and also contained hydrographic and road network information, as updated from the recently acquired satellite imagery.

The Project Document foresaw that some of these land cover maps would be prepared at both 1:100 000 and 1:250 000, to provide more detailed information for the priority agricultural areas at a scale of 1:100,000 and to present the other lands at the smaller scale of 1:250,000. However, upon completion and harmonization of the land cover map data, it was seen that the land cover classes mappable were such that there would be no technical advantage in the presentation of the data at a scale of 1:100 000 and that no data would be lost by presentation at the smaller scale. Indeed, as generation of plots of land cover for any specific area at any scale (1:100 0000 or even larger) would be possible from the digital database, coupled with the advantage of having the land cover maps at the same scale as the offset litho photomaps, resulted in a decision to forego the production of 1:100 000 maps.

To enhance and make more effective the local national usage of the 1:250 000 land cover maps, each map in the series was prepared using dual Dari and English languages for the map marginalia and the legend descriptions. These maps were to be distributed as boxed sets of 82 maps. The addition of a comprehensive text in Dari - to a much greater extent than originally envisaged - considerable enhanced the national usefulness of the product.

\subsubsection{National land cover map of Afghanistan}

A countrywide land cover map at a scale of 1:1250 000 was also prepared. This output had not been foreseen in the Project Document, but, upon completion of the data collection and collation work, the absence of a one-sheet, land cover of Afghanistan map was clearly noted, and so it was added to the project's outputs.

Furthermore, as it was expected that its comprehensive nature would make the one-sheet, land cover map of wider usefulness, it was decided not only to present the map using both Dari and English marginalia and legend, but also to print it in a relatively large number, i.e., 1000 copies.

The pre-printing quality control, and final modifications of the political and administrative boundaries of Afghanistan were completed in the post-project phase using FAO/TCP funds. 


\subsubsection{Provincial land cover atlas of Afghanistan}

A Provincial Land Cover Atlas, prepared in A3 size and comprising 32 separate, provincial land cover maps for both 1993 and 1972, together with both tabulated and graphic representations of the statistics of the land cover for each province for both years, was also prepared. In this atlas, in order to facilitate comparison between the 1993 and 1972 land cover datasets, the land cover classes in both datasets were variously grouped so as to obtain compatibility, resulting in a more meaningful comparison and analysis of the changes in the land cover over the period.

This atlas, which also includes discussion of the changes in the land cover of Afghanistan from 1972 to 1993, was again not foreseen as a project output per se, as, at the time of project formulation, it was believed that the extraction of maps and statistics would take place on an asrequired basis from the database which, it was assumed, would by that time be operational in Kabul.

However, since the continuation of the conflict in Afghanistan effectively precluded the immediate setting up of the system at $\mathrm{AGCHO}$, it was felt that the preparation and subsequent dissemination of a hardcopy product was essential to would make the information available to resource planners as soon as possible. Hence the decision to generate the provincial atlas, which should be an excellent managerial tool for officers responsible for management and planning of the natural resources of the country at national or provincial levels.

\subsubsection{Conclusion}

Clearly, all three land cover map products could be expected to be extremely useful tools in the planning and implementation of any future land-resource-related projects, in particular those related to agricultural development and rehabilitation. The availability of the maps and the related statistics when reconstruction after the consequences of the recent conflict would be of paramount importance has given them even more significance and value than perhaps originally envisaged.

It should be noted that FAO provided significant staff time as inputs, and FAO/TCP funding to cover travel of experts fellows from Afghanistan, to assist in the completion of the quality control and clearance of the final products. 


\subsection{LAND COVER DIGITAL DATABASE}

Probably the most important output of the project was the natural resources digital database. At the end of the project, the database included the land cover maps of Afghanistan for 1972 and 1993, as well as all major and secondary roads and the hydrographic network.

With the database and the equipment purchased for the implementation of the project, AGCHO should effectively be in a position to make available to any user the information of the database, at a variety of scales, in a very short time.

The structure of the database was such that query and access to information (such as maps at various scales, as well as statistics) was possible for national, provincial, $1^{\circ} \times 1^{\circ}$ and National Map Index coverages.

The project prepared detailed manuals describing the database and how to use it (see Appendix 4).

Furthermore, the database was such that it would be possible for AGCHO to add new layers of geocoded spatial thematic information - such as geological and hydrologic maps - into the database as it receives such information from national governmental organizations and agencies, United Nations agencies or other sources.

Lastly, it is worth stressing that the digital nature of the information in such a database not only greatly facilitates its maintenance and updating, but also considerably reduces the possibility of its destruction - a fate that befell a large number of traditional, paper-based maps maintained at $\mathrm{AGCHO}$.

\subsection{PILOT CHANGE DETECTION STUdIES}

\subsubsection{Vegetation change detection study}

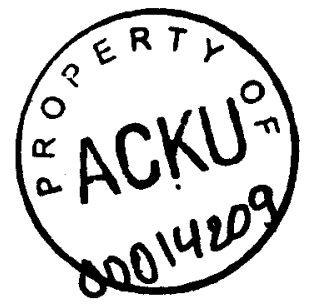

The first immediate objective of the project was to evaluate the utility of NOAA LAC data for future vegetation monitoring in Afghanistan. It was hoped that a methodology could be developed by which low-priced, coarse-resolution satellite data readily obtainable from NOAA satellites could be substituted for the expensive, high-resolution Landsat TM data for future monitoring of vegetation cover, particularly rangelands.

Appropriate NOAA data was therefore purchased and the necessary processing carried out. Vegetation indices of the country for two dates were prepared at appropriate scales. 
The results showed that the methodology, while promising, was still in a developmental stage and, as such, could not be effectively used for routine operational monitoring purposes in Afghanistan. Potentially, other satellites becoming available, such as the Russian RESEURS-01, could be used effectively for this purpose.

\subsubsection{Change detection using Landsat TM}

Another study carried out by the project was to use multi-temporal TM Landsat data to investigate vegetation cover changes in two pilot study areas: Mazari Sharif and Kandahar.

This study was not originally planned, but as the data was available and the data processing sub-contractor was willing to carry out the necessary processing, it was decided to implement this change detection study.

The results of the study, while incomplete due to the need for further refinement, indicated that while more control was required as to the selection of dates for the TM coverages, there was no doubt that the methodology, once refined and finalized, would provide AGCHO with the possibility of updating its database in an appropriately timely manner.

\subsection{GENERAL CONCLUSIONS}

The training and familiarization of the staff of AGCHO - the counterpart agency - as well as experts from other related organizations was inadequate, and so measures to rectify the situation were still outstanding. Such training would be particularly relevant vis-à-vis the operation and maintenance of the database, and basic computer training in general.

In view of the difficulties experienced in developing the database, and with due consideration for the present level of know-how in this respect in AGCHO, a much more comprehensive training programme than that originally envisaged would be necessary to attain reasonable selfsufficiency.

As ground truth activities had to be carried out through the medium of an NGO rather than by using AGCHO staff, the project lost the opportunity to train AGCHO staff in ground data collection techniques, since this training was necessarily given to the NGO's crews. At the same time, the operation of the programme - one that had been assumed to be easily, quickly and relatively cheaply executable - proved to be extremely time consuming and relatively expensive. 
The training of AGCHO staff in GPS technology and ground data collection techniques had therefore to be postponed.

Three factors conspired to delay project implementation:

- the initial estimates of the work inherent in digitizing the existing 1972 land cover maps and preparation of the 1993 land cover, involving the interpretation of 82 photomaps, without any possibility of ground verification by the interpreter, proved to be grossly underestimated and required considerably more technical time and effort than initially anticipated;

- there was a completely unforeseen need to carry out a very detailed and time consuming quality control of the data database towards the end of the project. The fact that at this time the project team had been dispersed and was no longer functioning as a unit only further exasperated the situation; and

- repeated changes in political and administrative boundaries during the project lifetime, coupled with the very difficult communication process for discussing and validating such changes, enormously affected the planning, and hence budgeting, of the project. This, while understandable in view of events in Afghanistan, and essential, if the final statistical extraction was to be meaningful, had perhaps the most negative impact on the project's scheduling.

While substantial savings were obtained by the employment of a part-time CTA for the project, there was no doubt that the intermittent availability of the CTA adversely affected the smooth running and continuity of the project, and, clearly, a full-time CTA should have been foreseen for work of such a complex nature. 


\section{RECOMMENDATIONS}

The project achieved its objective of providing a digital-based land cover database of Afghanistan in GIS format and capable of providing specialized cartographic outputs upon an as-needed basis, In addition the various maps were provided in hard form, and represent a major tool for those concerned with the rehabilitation and development of Afghanistan.

The information in the data base needs to be kept current, and it is recommended that every effort be made to maintain the database and to incorporate new information as it becomes available, with an update every three years at least. This will require ongoing support to AGCHO to allow it to maintain a cadre of experienced staff, to acquire new remote sensing data on a regular basis, and to upgrade its computer hardware and software at regular intervals.

The project was unable, for reasons outside its control, to fulfil its training objectives, and so these still remain valid. Training will be required both for technicians and users, and both initial and refresher training courses will be needed at regular intervals. It is recommended that assistance be sought to provide suitable training courses for the various categories of users and technicians. In particular, further training will be required in the maintenance and application of GIS technology for cartographic purposes and as a management tool.

It is important that the outputs of this project be available and used in future activities, and it is therefore recommended that they be properly archived so that they remain accessible.

It is recommended that the outputs of this project form the basis for the decision support system to assist in the rehabilitation of Afghanistan, as envisaged in UNDP/FAO pipeline project AFG/97/001. 
Appendix 1

PROJECT STAFF

Name

International

B. Jazayeri

A. di Gregorio

H. Palmer

A. Naizi

C. Verdecci

National

G. Jellani
Chief Technical Adviser

Senior mapping expert

GIS expert

Database specialist

Cartographer

National Project Director
Dates of Service Starting

Concluding
Jan. 1992

July 1991

June 1993

Jan. 1992
All project ${ }^{(1)}$

Dec. 1993

Dec. 1993

Dec. 1993

Dec. 1993

Note: (1) Intermittent; a total of 6 work-months. 
Appendix 2

FELLOWSHIPS AND STUDY TOURS

\section{A2.1 FELLOWSHIPS}

$\underline{\text { Name }}$

M.S. Partaw

H. Ghulam

\section{A2.2 STUDY TOURS}

G. Jellani

Darwesh

G. Jellani

Darwesh

G. Jellani ${ }^{(1)}$

A. Raouf ${ }^{(1)}$
Preparation of bilingual map products

Preparation of bilingual

map products

Finalization of bilingual

map products
Location

RSC, FAO,

Rome
Dates

10 April 1994

- 20 May 1994
RSC, FAO, $\quad 14-29$ May 1992

Rome

RSC, FAO,

Rome

RSC, FAO,

Rome
9 May 1993

- 23 June 1993

9 Oct. 1996

- 14 Nov. 1996

Note: $(1)$ = financed from FAO/TCP funds. 


\section{Appendix 3}

\section{MAJOR ITEMS PROCURED BY THE PROJECT}

Quantity

1 set

$\underline{\text { Item }}$

Cost

(\$US)

KFA-1000 Film positives

3600

2 sets

Landsat TM products

42500

1 set

Satellite photomaps

1898

4

Software module

1 set

SPOT satellite computer compatible tapes

9945

1 set

KFA-1000 film positives

5750

1 set

KFA-1000 film positives

3610

1

Image processing software (DOS)

76300

28 items Computer hardware and software

20450

1

ARC/INFO starter kit (Training kit)

88537

1 set

Landsat TM digital satellite data

5000

2125

1 set

Landsat TM digital satellite data

4250

Cabinets

4850

8 items

Plotting supplies for map reproduction

1233

1 set

Landsat TM data

30375

Registration punch

9275

1 set

Computer-scribed plots

10800

1 set

Landsat scenes

3300

Map cabinet

12 items

Computer equipment

1000

Global positioning system (GPS) receiver

115435

2 sets

Landsat satellite products

20000

1 set

Office supplies

171860

1 set

Digital hydrography files

116

1 set

Remote sensing equipment

16554

1 set

Graphic equipment

1940

1 set

Digital data files

12079

Polyester base for printed output

11737

Office supplies 


$\begin{array}{llr}1 \text { set } & \text { Photographic colour prints } & 7600 \\ -- & \text { Office stationary and equipment } & 1286 \\ -- & \text { Photographic materials } & 17549 \\ -- & \text { Photographic materials } & 19472 \\ 1 & \text { Punch machine (Maxi KLS) } & 8835 \\ 1 & \text { Personal computer with accessories } & 8125 \\ 1 & \text { Personal computer with accessories } & 4795 \\ 1 \text { set } & \text { Computer output device + accessories } & 4225 \\ 1 & \text { 19" high resolution VDU } & 4469 \\ 1 \text { set } & \text { Computer output device + accessories } & 7313 \\ 1 & \text { A0 inkjet plotter + driver software } & 15938 \\ 1 & \text { A4 flatbed } 400 \text { dpi colour scanner (HP ScanJet) } & 2438 \\ 1 & 1.5 \text { kvA uninterrupible power supply } & 4313\end{array}$

Specialized GIS, image processing application and associated software (with related documentation and manuals) obtained included ARC/INFO, ARC/VIEW, ARC/CAD, EASI/PACE, ILLWIS, Sitback (PC or LAN Backup), EasyCopy/PC Plus, Systos Plus (Backup SW for Exabyte), NovaPaint (for Novajet Plotter), Xtree Gold, Photo Vision (Toshiba), Graph-in-the-box, PC TOOLS for Windows and DOS, dBASE IV, SPSS for Windows, and Adobe Type Manager. 
Appendix 4

\section{PROJECT PUBLICATIONS}

In addition to the various cartographic and Photomap outputs mentioned in the text, there were two manuals:

Database documentation. May 1995. Prepared for Afghanistan Geodesy and Cartography Head Office by UNDP/FAO project AFG/90/002, Utilization of remote sensing for inventory and monitoring of agricultural land in Afghanistan. $40 \mathrm{pp}$.

User's manual. May 1995. Prepared for Afghanistan Geodesy and Cartography Head Office by UNDP/FAO project AFG/90/002, Utilization of remote sensing for inventory and monitoring of agricultural land in Afghanistan. $64 \mathrm{pp}$.

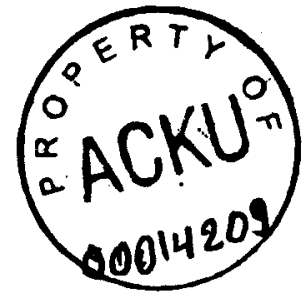

